\title{
Managing Professions for Knowledge Management
}

\author{
Enrico Scarso, University of Padua, Italy \\ Ettore Bolisani, University of Padua, Italy
}

\begin{abstract}
In the last years, Knowledge Management (KM) studies have focused on the foundations of this "new managerial discipline". Today, there is an increasing need to transform the theoretical speculations into managerial tools, and to find solutions to practical questions concerning daily KM activity. A key issue that still requires investigation regards the management of human resources devoted to KM. The paper analyzes this topic by means of an in-depth investigation of the relevant experience of some leading companies. In particular it examines the problem of managing new roles and tasks for KM, the issue of developing structured KM units, and the question of evaluating KM activities. A discussion of the possible implications for research and management is carried out in the conclusion.
\end{abstract}

Keywords: $\quad$ Business Management, CKO, Human Resource Management, Knowledge Management Roles, Knowledge Management Tasks, Knowledge Workers

\section{INTRODUCTION}

From its origin, Knowledge Management(KM) has been attracting the interest of the leading US and European companies that have rapidly implemented KM programs (Grossman, 2006). Hence, $\mathrm{KM}$ is becoming an essential ingredient of management practices, and it needs to be integrated with the other well established management functions.

One issue that deserves explicit consideration concerns the links between Human Resource Management (HRM) and KM (Edvardsson, 2008; Gloet, 2006). Actually, human resources are involved in $\mathrm{KM}$ in many ways, and broadly speaking the relationship between

DOI: $10.4018 / \mathrm{jkm} .2011070105$
KM and HRM can be seen under two different perspectives. The first one considers employees as the ultimate users of the knowledge an organization possesses (Oltra, 2005). Accordingly, the link between HRM and KM is seen in relation to aspects such as the organization of training activities, the provision of knowledgebased services, the facilitation of employees' interaction, etc.

The second perspective focuses on the fact that a successful implementation of KM requires personnel specifically employed and trained for managing such initiatives (Burstein et al., 2010; Edvardsson, 2008). This view argues that the adoption of appropriate knowledge-related HRM practices can influence the effectiveness of KM activities (Burstein et al., 2010; Cabrera \& Cabrera, 2005), and the practical 
implementation of $\mathrm{KM}$ requires changes in the way people are managed, for instance with the aim of influencing individuals to assume a knowledge-sharing attitude.

This paper especially focuses on this second aspect, which has been relatively less considered in the literature. In particular, it investigates the challenges posed to HRM by the emerging KM-related activities. The recent literature and the empirical evidence are surveyed with the aim to underline important issues, relating to the nature and the contents of the new professions, the staffing policy, the performance appraisal, the rewards system. Based on this analysis, we discuss the main practical aspects of HRM in KM programs, and make some important points for a future research agenda.

\section{THE ROLE OF PEOPLE IN KNOWLEDGE MANAGEMENT}

Setting the grounds of $\mathrm{KM}$ as a managerial discipline has proven to be a difficult task that is still challenging researchers and practitioners. This is certainly due to the youth of the field and to the fact that several disciplines are contributing to its development (Baskerville $\&$ Dulipovici, 2006). In addition, it is the term knowledge itself that can be confusing. In the $\mathrm{KM}$ literature, knowledge is often defined in comparison with the notion of information. According to Holsapple (2003) information consists of data that have been organized for a particular use (i.e. qualities or measures of phenomena or facts, like, for instance, prices, sales, inventories, etc.), while knowledge is a combination of information, ideas, experience and insights that guide actions and decisions. Therefore, although knowledge is based on information, deriving knowledge from information requires human judgment, and is based on context and experience.

According to Holsapple and Joshi (2006), $\mathrm{KM}$ can be defined as the deliberate and organized efforts made by individuals or organiza- tions to expand, cultivate and apply available knowledge in ways that can add value to their activity. To put it in a nutshell, KM consists of a set of techniques and tools to make the right knowledge available to the right people in the right moment.

Arecent study (Heisig, 2009) aimed at comparing 160 different KM frameworks around the world shows that KM is generally seen as a set of main activities (knowledge creation; knowledge storage; knowledge sharing; and knowledge application) whose effectiveness is based on a proper mix of human, structural, cultural, and managerial factors.

In the past, two main approaches to KM have been followed by companies, one associated to a hard technology-oriented notion, the other to a more human-oriented vision (Lee \& Choi, 2003; Newell et al., 2006). The technology-oriented view derives from Information Systems scholars: knowledge is considered to be an object that can be detached from its holder, and can hence be stored and transferred by means of a technological device. Conversely, the human-oriented approach considers knowledge as inseparable from the mind of individuals and as a result of social processes. Thus, although both views ascribe an essential role to computers and ICT systems, while in the technology-oriented approach technologies are the cornerstone of KM and they are seen as a way to automate cognitive tasks, in the human-oriented approach they are considered a set of enabling tools that may or may not be of use to human beings for facilitating their cognitive activities.

The experience seems to confirm that the effectiveness of KM projects depends on both technical and non-technical elements. The large majority of initiatives carried out by companies resort to a mixed set of solutions, which include both technical tools (e.g. knowledge repositories, knowledge portals, web directories) and organizational arrangements (e.g. teams, communities of practice, meetings). 
13 more pages are available in the full version of this document, which may be purchased using the "Add to Cart" button on the product's webpage:

www.igi-global.com/article/managing-professions-knowledgemanagement/56365?camid $=4 \mathrm{v} 1$

\section{Related Content}

Intellectual Capital: How Knowledge Creates Value

Maria do Rosário Cabrita, Virgílio Cruz Machado and António Grilo (2011).

Knowledge Management for Process, Organizational and Marketing Innovation: Tools and Methods (pp. 237-252).

www.igi-global.com/chapter/intellectual-capital-knowledge-creates-

value $/ 46756$ ?camid $=4 \mathrm{v} 1 \mathrm{a}$

Exploring Strategies for Capturing Customer's Tacit Knowledge in Customer Integration Methods

Ulrich Bretschneider and Shkodran Zogaj (2016). International Journal of Knowledge Management (pp. 1-19).

www.igi-global.com/article/exploring-strategies-for-capturing-customers-tacitknowledge-in-customer-integration-methods/170540?camid=4v1a

Factors Affecting KM Implementation in the Chinese Community Yang Lin and Kimiz Dalkir (2012). Conceptual Models and Outcomes of Advancing Knowledge Management: New Technologies (pp. 1-23). www.igi-global.com/chapter/factors-affecting-implementation-chinesecommunity/62414?camid=4v1a

Knowledge Management Success Models Murray E. Jennex (2006). Encyclopedia of Knowledge Management (pp. 429-435). www.igi-global.com/chapter/knowledge-management-successmodels $/ 16981$ ?camid $=4 \mathrm{v} 1 \mathrm{a}$ 